\title{
BACTERIAS ENDÓFITAS ASOCIADAS A LOS GÉNEROS Cyperus Y Paspalum EN SUELOS CONTAMINADOS CON MERCURIO
}

\section{ENDOPHYTIC BACTERIA ASSOCIATED TO GENUS Cyperus AND Paspalum IN SOILS WITH MERCURY CONTAMINATION}

\begin{abstract}
Alexander Pérez ${ }^{1}$, Dalila Martínez² ${ }^{2}$ Zafiro Barraza ${ }^{3}$, José Marrugo ${ }^{4}$
${ }^{1}$ Dr. Agr. Universidad de Sucre, Facultad de Ciencias Agropecuarias, Grupo de investigación en Bioprospección Agropecuaria, e-mail: alexander.perez@unisucre.edu.co; ${ }^{2}$ Biol. Universidad de Sucre, cM.Sc. en Ciencias Ambientales, Grupo de investigación en Bioprospección Agropecuaria, e-mail: dalilamartinez23@hotmail.com; ${ }^{3}$ Biol. Universidad de Sucre, M.Sc. en Biotecnología, Grupo de investigación en Bioprospección Agropecuaria, e-mail: zafiro.barraza@unisucre.edu.co; Campus Universitario Puerta Roja, carrera 28 No. 5 - 267, Sincelejo, Sucre, Colombia. ${ }^{4}$ Dr. Ing. Qui. Universidad de Córdoba, Facultad de Ciencias Básicas, Grupo de investigación de Aguas, Química Aplicada y Ambiental, e-mail: jmarrugo@correo.unicordoba. edu.co; Campus universitario, carrera 6 No. 76-103, Montería, Córdoba, Colombia.
\end{abstract}

Rev. U.D.C.A Act. \& Div. Cient. 19(1): 67-76, Enero-Junio, 2016

\section{RESUMEN}

El objetivo de este estudio fue aislar e identificar bacterias endófitas resistentes a mercurio, asociadas a los géneros Cyperus y Paspalum, en suelos de Mina Santa Cruz, Bolívar, Colombia. Para ello, se colectaron muestras de suelo y de plantas herbáceas, con el fin de evaluar, mediante espectrofotometría de absorción atómica por vapor frío, la concentración de mercurio total. Se utilizaron muestras de tejidos vegetales para el aislamiento y la determinación poblacional de bacterias endófitas. La resistencia a mercurio in vitro de los aislados, se evaluó en agar nutritivo suplementado con $\mathrm{HgCl}_{2}$; los aislados resistentes fueron identificados, a nivel molecular. La concentración de mercurio total en el suelo de Mina Santa Cruz fue de $4,7 \mathrm{mg} \mathrm{kg}^{-1}$. Las especies vegetales colectadas fueron Paspalum arundinaceum, Cyperus luzulae y Cyperus laxus. La mayor concentración de mercurio en los tejidos vegetales fue encontrada en raíz, con un rango de 1,5 a $3,8 \mathrm{mg} \cdot \mathrm{kg}^{-1}$. Las especies $P$. arundinaceum y $C$. laxus presentaron las mayores densidades poblacionales de endófitas en sus tejidos $1 \times 10^{8}$ UFC, aproximadamente. Se aislaron siete bacterias endófitas resistentes, a concentraciones de 350 y 400 ppm de mercurio. De los tejidos de $P$. arundinaceum, se aislaron cuatro bacterias, que corresponden a Burkholderia cepacia, Burkholderia sp. y dos aislados tuvieron gran similitud con Bacillus sp.; para C. luzulae, se aislaron dos endófitas resistentes a mercurio, una identificada como Ralstonia solanacearum y, la otra, como Burkholderia sp.; para C. laxus, un aislado que hace parte de la familia Xanthomonadaceae, también tuvo resistencia a mercurio.

Palabras clave: Minería, metales pesados, resistencia, herbáceas.

\section{SUMMARY}

The objective of this study was to isolate and identify endophytic bacteria mercury resistant, associated to the genus Cyperus and Paspalum in the locality of Mine Santa Cruz, Bolivar, Colombia. Soil and herbaceous plant samples were collected to evaluate total mercury concentration in soil and plant tissues, using cold-vapour atomic absorption spectrophotometry. The plant tissue samples were used for isolation and population determination of endophytic bacteria. The mercury resistance of isolates was evaluated in nutrient agar supplemented with $\mathrm{HgCl}_{2}$, the resistant isolates were identified molecularly. The total concentration of mercury in the soil of Mine Santa Cruz was $4.7 \mathrm{mg} \cdot \mathrm{kg}^{-1}$. Plant species collected were Paspalum arundinaceum, Cyperus luzulae and Cyperus laxus. The highest concentration of mercury in plant tissues was found in root with a range of 1.5 to $3,8 \mathrm{mg} \cdot \mathrm{kg}^{-1}$. The species $P$. arundinaceum and C. laxus presented the greater population densities of endophytic bacteria in their tissues about $1 \times 10^{8}$ UFC. Seven endophytic bacteria, resistant to concentrations of 350 and 400ppm of mercury were isolated. From $P$. arundinaceum tissues four bacteria corresponding to Burkholderia cepacia, 
Burkholderia sp. and two isolates similar to Bacillus sp., from C. luzulae two endophytic bacteria resistant to mercury, one identified as Ralstonia solanacearum and the other one as Burkholderia sp.; from C. laxus tissues one bacteria belonging to family Xanthomonadaceae, resistant to mercury, was isolated.

Key words: Mining, heavy metals, resistance, herbaceous plants.

\section{INTRODUCCIÓN}

El mercurio, se constituye como uno de los metales tóxicos que más afecta el bienestar de los ecosistemas y pone en riesgo a la salud humana. A nivel mundial, se ha confirmado que la exposición a altas concentraciones de mercurio genera efectos adversos a la salud, tales como desórdenes en el sistema nervioso central, cardiovascular, inmune y renal (Holmes et al. 2009). En las plantas las altas concentraciones de mercurio inducen estrés oxidativo, por la generación de especies reactivas de oxígeno, inhibición del crecimiento y peroxidación lipídica (Cui et al. 2014). Este metal también afecta la comunidad microbiana del suelo que soporta el ciclado de nutrientes, lo cual, disminuye la fertilidad y la descomposición de materia orgánica, en sitios contaminados.

En Colombia, la minería de oro es desarrollada por personas en condición de vulnerabilidad, sin asistencia técnica y con métodos muy rudimentarios, que generan un enorme impacto ambiental. Se calcula que el mercurio total liberado al ambiente puede alcanzar las 150t, dándole a Colombia un vergonzoso primer lugar, como el país que más contaminación de mercurio genera per cápita, en esta actividad (Cordy et al. 2011). El corregimiento de Mina Santa Cruz perteneciente al municipio de Barranco de Loba, sur de Bolívar, presenta una alta contaminación con mercurio en matrices ambientales, debido a las corrientes de amalgamación que salen de los molinos utilizados en la minería artesanal de oro, realizada en el casco urbano, de dicha población (Argumedo et al. 2013).

Actualmente, para mitigar los efectos de la contaminación con metales, se están utilizando técnicas, como la fitorremediación, que es una tecnología efectiva, económica y amigable con el medio ambiente, que está recibiendo mucha atención, a nivel mundial. El éxito de la fitorremediación depende de la habilidad de la planta para tolerar altas concentraciones de metales y producir gran cantidad de biomasa (Ma et al. 2011). Las bacterias endófitas que viven en los tejidos internos de las plantas favorecen la eficiencia del proceso de fitorremediación y aumentan la producción de biomasa vegetal, mediante tres mecanismos: incremento de la superficie de la raíz y la producción de pelos radiculares; incremento de la disponibilidad de los metales y el incremento en la transferencia de metales solubles, desde la rizósfera hasta la planta (Weyens et al. 2009; Ma et al. 2011); algunos, de las bacterias endófitas estudiados.

Especies de bacterias endófitas asociadas a tejidos de plantas que crecen en suelos contaminados por mercurio pueden estar resistiendo in situ a dicho metal; para conocer esta realidad, se hizo necesario realizar el presente estudio, con el objetivo de aislar e identificar bacterias endófitas asociadas a los géneros Cyperus y Paspalum, que crecen en suelos contaminados con mercurio, en el departamento de Bolívar.

\section{MATERIALES Y MÉTODOS}

Identificación de zonas contaminadas con mercurio en el departamento de Bolívar. Para la identificación, se hizo un levantamiento de la información bibliográfica que reporta ambientes contaminados con este metal pesado, en el caribe colombiano (Vidal et al. 2010; Argumedo et al. 2013). El sitio seleccionado correspondió al corregimiento de Mina Santa Cruz, jurisdicción del municipio de San Martin de Loba, ubicado en el sur de Bolívar, Colombia. Las coordenadas geográficas de este corregimiento son: $08^{\circ} 42^{\prime} 31^{\prime \prime}$ latitud Norte y 74¹1'54,6” longitud Este. La comunidad de Mina Santa Cruz, se dedica, principalmente, a la explotación artesanal de oro, que se desarrolla dentro del casco urbano. Dicho proceso conlleva a concentraciones elevadas de mercurio en suelo, debido a las corrientes acuosas que salen de los molinos de amalgamación y a la quema de mercurio, para purificación de oro.

Recolección e identificación del material vegetal. El muestreo, se realizó aleatoriamente en forma de zig-zag, colectando, al mismo tiempo, muestras de suelos hasta completar $1 \mathrm{~kg}$ y 10 plantas completas (raíz, tallo y hojas), por cada especie. Para la recolecta y la selección de las plantas, se tuvieron en cuenta aquellas especies con buen estado fitosanitario y sin presencia de síntomas de fitotoxicidad. Las muestras de suelo y de plantas herbáceas fueron conservadas, identificadas y transportadas al laboratorio de investigaciones microbiológicas, de la Universidad de Sucre. Una parte de las muestras de suelo y de tejido fueron enviadas a la Universidad de Córdoba, para la determinación de la concentración total de mercurio; otra parte de la muestra de suelo fue destinada para análisis fisicoquímico. Una porción del material vegetal fue utilizada para identificación taxonómica, en el herbario Nacional Colombiano, de la Universidad Nacional de Colombia y, la otra, para el aislamiento y la determinación de bacterias endófitas asociadas por tejido.

Análisis físico-químico del suelo. Se colectaron las muestras en una extensión de una hectárea, marcando los puntos de muestreo al azar, abarcando toda el área. Para la 
toma de muestra, se empleó la metodología recomendada por el IGAC (2015). Se tomaron $100 \mathrm{~g}$ de suelo, se extendió sobre un plástico y se secó a temperatura ambiente, en un lugar seco, durante cuatro días; luego, se empleó un tamiz redondo de $2 \mathrm{~mm}$, para obtener tierra fina. Se utilizó la metodología de Olarte et al. (1979), para evaluar parámetros, como el pH, la materia orgánica, el fósforo, el CIC, el calcio, el magnesio, el potasio, el sodio, el aluminio intercambiable, la textura, la saturación de calcio, la saturación de magnesio, la saturación de sodio, la saturación de aluminio, la relación calcio/magnesio, la conductividad eléctrica y la densidad aparente.

Concentración de mercurio en muestras de suelo y plantas. Las muestras de plantas, se dividieron en diferentes tejidos raíz, tallo y hojas, que fueron lavados con agua destilada, para eliminar partículas minerales, adsorbidas por su superficie. Luego, cada tejido se depositó en bolsas de papel y se secó en horno a $60^{\circ} \mathrm{C}$, durante $24 \mathrm{~h}$. Para determinar el mercurio total en dichas muestras, se tomaron $0,5 \mathrm{~g}$ de material seco y se le adicionó una mezcla ácida $\mathrm{HNO}_{3} / \mathrm{H}_{2} \mathrm{O}_{2}(5+2 \mathrm{~mL})$. Por otra parte, del suelo, previamente secado, se tomaron $0,5 \mathrm{~g}$ y se le adicionaron $10 \mathrm{~mL}$ de $\mathrm{HNO}_{3}$ al $65 \%$. Tanto las muestras de suelo como las de plantas fueron procesadas en un horno microondas Milestone ETHOS TOUCH serie 127697 y se analizó el mercurio total por espectrofotometría de absorción atómica por vapor frío, según procedimientos descritos en Marrugo-Negrete et al. (2015).

Aislamiento de bacterias endófitas. Se llevó a cabo en el laboratorio de investigaciones microbiológicas de la Universidad de Sucre. Para ello, las muestras de material vegetal fueron sometidas a un proceso de desinfección superficial, descrito por Pérez et al. (2010). Luego de este proceso, cada tejido se maceró en un mortero de porcelana con nitrógeno líquido, hasta obtener una mezcla homogénea. De cada homogenizado, se prepararon diluciones seriadas, que se sembraron por técnica de difusión, sobre la superficie de agar R2A y se incubaron a $28^{\circ} \mathrm{C}$, por $72 \mathrm{~h}$. La densidad poblacional de bacterias endófitas por tejido, UFC/g de tejido, se estimó por conteo directo de colonias en placas. Durante el conteo, se observaron y se seleccionaron las colonias en cuanto a forma, aspecto de la superficie, color y tamaño. Los morfotipos seleccionados fueron purificados y mantenidos en agar R2A (Pérez et al. 2015).

Evaluación in vitro de la resistencia a mercurio de bacterias endófitas. Los aislados bacterianos fueron sembrados en agar nutritivo suplementado con $\mathrm{HgCl}_{2}$, a concentraciones de 100, 150, 200, 250, 300, 350 y 400 ppm; luego, se incubaron a $29^{\circ} \mathrm{C}$, por 7 días (Sorkhoh et al. 2010).
Identificación molecular de bacterias endófitas. La extracción de ADN genómico de bacterias endófitas resistentes a mercurio, se realizó mediante el protocolo planteado por Oliveira et al. (2013). Para la amplificación del gen ARNr 16S, se utilizaron tres juegos de cebadores específicos: F BLS342 (5' CAGCAGTAGGGAATCTTC 3') y R 1392 (5' ACGGGCGGTGTGTACA 3'), para la clase firmicutes; F 9483 (5' CGCACAAGCGGTGGATGA 3') y R 1492 (5' TACGG(C/T) TACCTTGTTACGACTT 3'), para la clase betaproteobacteria; FD2 (5' AGAGTTTGATCATGGCTCAG 3') y RP1 (5' ACGGTTACCTTGTTACGCTT 3'), para la clase gammaproteobacteria. Las condiciones utilizadas en cada reacción de amplificación, se basaron en el protocolo descrito por Oliveira et al. (2013), empleando un termociclador mastercycler nexus eppendorf. Los productos obtenidos de la amplificación, se purificaron y se secuenciaron en Macrogen Corea. Las secuencias obtenidas, se compararon con las almacenadas en el Genbank. El alineamiento de las bases, se realizó en el programa Clustal w, su análisis y corrección en el programa Mega 5, las inferencias filogenéticas fueron obtenidas por el método de máxima similitud, basado en el modelo kimura-2-parámetro.

Análisis estadístico. Se utilizó un diseño completamente al azar con un solo factor, utilizando tres repeticiones. Para establecer diferencias entre las densidades poblacionales de las tres especies de pasto recolectadas en Mina Santa Cruz, se realizó una transformación de los datos para ajustarlos a la normalidad y se aplicó una ANOVA, utilizando el programa estadístico Infostat versión gratuita.

\section{RESULTADOS Y DISCUSIÓN}

Identificación del material vegetal. Se recolectaron tres especies de plantas establecidas en la región de Mina Santa Cruz: Paspalum arundinaceum Poiret, Cyperus luzulae (L.) Rottb. ex Retz y Cyperus laxus Vahl. La primera especie, $P$. arundinaceum, se conoce en la región como pasto, pertenece a la familia poaceae, se caracteriza por tener reproducción sexual y ser perenne y tiene una gran importancia económica, al ser utilizada para la producción de forraje (Evers \& Burson, 2004). Por su parte, las especies C. luzulae y C. laxus, son conocidas en la región como coquito y hierba, respectivamente, ambas pertenecen a la familia cyperaceae, poseen reproducción sexual, son perennes y arvenses, están localizadas, principalmente, en áreas abiertas y ambientes perturbados (Bryson \& Carter, 2008), tal como ocurre en Mina Santa Cruz.

Análisis físico-químico del suelo. Los resultados de los parámetros físico-químicos encontrados en la muestra de suelo recolectada en la zona de Mina Santa Cruz, se muestran en la tabla 1 . 
Tabla 1. Análisis físico-químico suelo de Mina Santa Cruz.

\begin{tabular}{|l|c|l|c|}
\hline \multicolumn{1}{|c|}{ Parámetro } & Valor & \multicolumn{1}{c|}{ Interpretación } & Valores de referencia \\
\hline pH (Agua 1:1 P/N) & 4,39 & Extremadamente ácido & $5,80-7,20$ \\
\hline Materia orgánica (\%) & 0,10 & Contenido muy pobre & $2,0-4,0$ \\
\hline Fósforo (ppm), Bray II & 17,76 & Contenido moderado & $15-30$ \\
\hline C.I.C. (meq/100 gr de suelo) & 9,00 & Contenido pobre & $10-20$ \\
\hline Calcio (Cmol.kg suelo) $^{-1}$ & 2,20 & Contenido muy pobre & $2-7$ \\
\hline Magnesio (Cmol.kg-1 suelo) & 1,30 & Contenido muy pobre & $0,2-0,4$ \\
\hline Potasio (Cmol.kg ${ }^{-1}$ suelo) & 0,02 & Contenido muy pobre & $<1,0$ \\
\hline Sodio (Cmol.kg suelo) $^{-1}$ & 1,70 & Contenido abundante & $<0,2$ \\
\hline $\begin{array}{l}\text { Aluminio intercambiable (Cmol.kg } \\
\text { suelo) }\end{array}$ & 5,59 & Contenido excesivo & Franco arcilloso \\
\hline Textura (M. Bouyoucos) & F.A. & Franco arenoso & $20-50$ \\
\hline Arena (\%) & 57,25 & & $20-60$ \\
\hline Arcilla (\%) & 15,00 & & $20-70$ \\
\hline Limo (\%) & 27,75 & & $50-70$ \\
\hline Saturación de calcio (\%) & 20,35 & Contenido pobre & $20-30$ \\
\hline Saturación de magnesio (\%) & 12,03 & Contenido moderado & $<6,0$ \\
\hline Saturación de sodio (\%) & 15,73 & Contenido abundante & $<5,0$ \\
\hline Saturación de aluminio (\%) & 51,24 & Contenido excesivo & $2-4$ (normal) \\
\hline Relación calcio /magnesio & 1,69 & Baja & $<2.000$ \\
\hline Conductividad eléctrica (MicroS/cms) & 386 & Suelo sódico & \\
\hline
\end{tabular}

La tabla indica que los suelos presentaron las siguientes características: Valores de $\mathrm{pH}$ extremadamente ácido; contenidos de materia orgánica, de calcio, de magnesio y de potasio, muy pobre; contenido de fósforo y porcentaje de saturación de magnesio, moderado; capacidad de intercambio catiónico y porcentaje de saturación de calcio, deficiente; abundantes contenidos de sodio; contenido abundante de aluminio y textura franco arenosa presente.

La presencia de un $\mathrm{pH}$ extremadamente ácido encontrado en la zona de estudio, quizá, indica que la absorción del mercurio es alta y, como consecuencia, es fácilmente transportado en el suelo por escorrentía hacia cuerpos de agua aledaños, lo que concuerda con lo reportado por Kabata-Pendias (2011) y Terán-Mita et al. (2013). Asimismo, el contenido excesivo de aluminio en estos suelos está muy relacionado con el $\mathrm{pH}$ ácido del mismo, lo que podría causar inhibición del crecimiento radical y, como resultado, reducción en la toma de agua y de nutrientes por parte de las plantas (CasierraPosada \& Aguilar-Avendaño, 2007).

Con relación a la capacidad de intercambio catiónico deficiente del suelo en la zona de estudio es causada, principalmente, por la baja cantidad de materia orgánica y el bajo contenido de arcilla de dicho suelo. Valores bajos de CIC afectan significativamente el contenido de calcio, de magnesio y de potasio, necesarios para el crecimiento y la nutrición de las plantas (Casierra-Posada \& AguilarAvendaño, 2007). Con respecto a la conductividad eléctrica, los suelos de Mina Santa Cruz son suelos sódicos, en los cuales, la presencia de sodio supera el $15 \%$, en el complejo de intercambio del suelo; esto hace, que sean físicamente inestables, que se desmenucen y se agrieten cuando se secan y se hundan cuando están húmedos. Cuando se endurecen son relativamente impermeables al agua, favoreciendo la escorrentía que transporta arcilla en suspensión, materia orgánica y nutrientes, lo que limita el crecimiento de plantas, como el arroz y el maíz (Sánchez \& Curetti, 2006).

Concentración de mercurio en muestras de suelo y de plantas. Las concentraciones de mercurio en suelos, generalmente, oscilan entre 0,01 y $0,2 \mathrm{mg} \cdot \mathrm{kg}^{-1}$, de acuerdo a lo reportado por Adriano (2001), pero se pueden incrementar, significativamente, en suelos afectados por la minería. Esto se evidenció en la concentración de mercurio del suelo de Mina Santa Cruz, cuyo valor fue de $4,7 \mathrm{mg} \cdot \mathrm{kg}^{-1}$, considerándose un suelo de categoría tóxico, por encontrarse dentro del rango de $0,3-5 \mathrm{mg} \cdot \mathrm{kg}^{-1}$; a estas concentraciones, el mercurio comienza a inhibir procesos en el suelo, tales como la respiración microbiana, la mineralización y la nitrificación (Poschenrieder \& Barceló, 2003; Kabata-Pendias, 2011). 
Respecto a las concentraciones de mercurio registradas en los tejidos de las tres especies de plantas, se observaron diferencias, como se muestra en la figura 1.

Cabe señalar, que la raíz fue el tejido en todas las especies estudiadas que mayor concentración de mercurio presentó, seguido por las hojas y, por último, el tallo. Marrugo-Negrete et al. (2015) confirman la acumulación de mercurio en mayor proporción en las raíces que en las partes aéreas de las plantas; lo anterior se explica, debido a que las raíces de las plantas están expuestas directamente al mercurio del suelo y, sobre ellas, se adhiere una gran cantidad del metal para evitar los efectos tóxicos, en las partes superiores de la planta (Wang \& Greger, 2004).

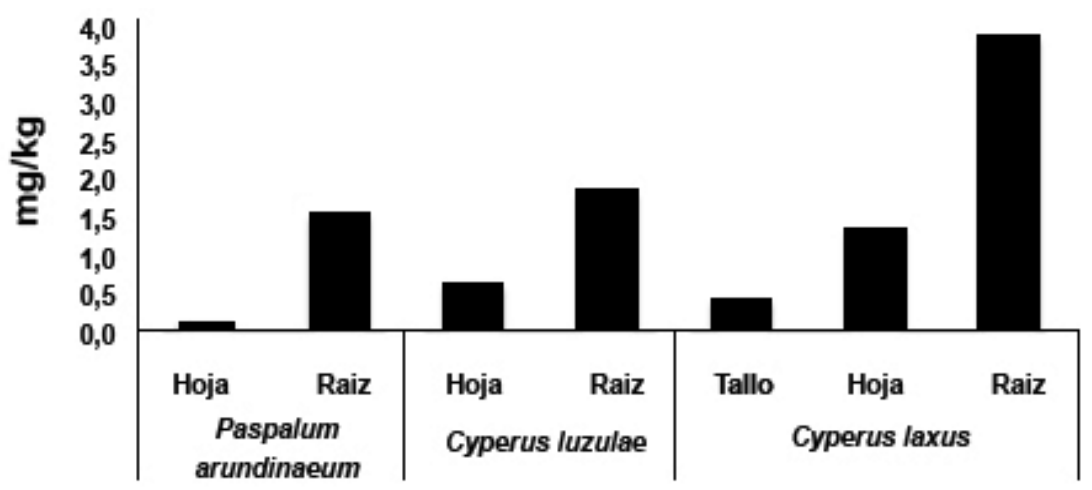

Especies vegetales (tejidos)

Figura 1. Concentración de mercurio en los tejidos de las tres especies de plantas establecidas en la zona de Mina de Santa Cruz, Bolívar, Colombia.

Por otra parte, la mayor concentración de mercurio en hojas, con respecto a tallos, se debe a que éstas son el receptor final del metal en la planta y allí cambia su estado de oxidación de $\mathrm{Hg}^{2+} \mathrm{a} \mathrm{Hg}^{\circ}$, debido a que es fitoquelado y acumulado en las vacuolas, como mecanismo de resistencia tóxica (Moreno et al. 2008). Además, gran parte del metal que llega a las hojas es potencialmente fitovolatilizado, lo que implica que no todo el mercurio que llega a esta parte de la planta es acumulado (Vidal et al. 2010).

Con respecto al tallo, la baja concentración de mercurio contenida en éste, se encuentra relacionada con la función que cumple dicho tejido, puesto que se encarga de transportar agua, minerales y alimentos a otras partes de la planta, como las hojas y no tiene como propósito acumular metal (Marrugo-Negrete et al. 2015).

Cyperus laxus tuvo la mayor concentración de mercurio en sus tejidos y, según Escalante-Espinosa et al. (2005), se considera una especie idónea para llevar a cabo procesos de fitorremediación, de forma satisfactoria. Esta especie, según Escalante-Espinosa et al. (2005) y López-Martínez et al. (2008), esta reportada como fitorremediadora de suelos contaminados con hidrocarburos, pero su excelente estado fitosanitario a concentraciones altas de mercurio y su abundancia en la zona de estudio, la convierten en una especie con gran potencial fitorremediador. Se ha demostrado, según Kabata-Pendias (2011), que a partir de 1 a $8 \mathrm{mg} \cdot \mathrm{kg}^{-1}$ se establece un nivel crítico de mercurio para el crecimiento de las plantas, lo cual, induce estrés oxidativo por especies reactivas de oxígeno y cambios visibles en su fisiología (Yadav, 2010).

Densidad poblacional de bacterias endófitas. Se aislaron un total de 99 morfotipos de bacterias endófitas asociadas a la especie $P$. arundinaceum; 83 morfotipos, para C. luzulae y 93 morfotipos, para C. laxus. El análisis de varianza de la densidad poblacional de bacterias endófitas, para las tres especies de plantas, mostró diferencias altamente significativas ( $p<0,01$ ), tal como se observa en la figura 2 , siendo las especies $P$. arundinaceum y $C$. laxus las que presentaron las mayores densidades poblacionales de bacterias endófitas en sus tejidos, con valores promedios de $1,3 \times 10^{8}$ y $1,2 \times 10^{8} \mathrm{UFC} / g$ de tejido, respectivamente, mientras que $C$. luzulae fue la especie con menor densidad de bacterias endófitas, con un promedio de $2,7 \times 10^{7} \mathrm{UFC} / \mathrm{g}$ de tejido.

Al comparar estos valores con la densidad poblacional de bacterias endófitas aisladas de otros plantas herbáceas, como Bothriochloa pertusa, también conocida como pasto colosuana, según lo demostrado por Pérez et al. (2010), el rango estuvo entre $3,4 \times 10^{3}$ a $5,3 \times 10^{4}$ UFC, mientras que la densidad poblacional de endófitas de las plantas de 
Mina Santa Cruz fue mucho mayor, con un rango de 2,8 $\mathrm{x}$ $10^{7}$ a $1,2 \times 10^{8}$ UFC. Lo anterior puede ser ventajoso para las plantas de los géneros Paspalum y Cyperus de Mina Santa Cruz, pues la gran densidad de bacterias endófitas que poseen, según Ma et al. (2011), ayuda a las plantas a crecer bajo condiciones de estrés, debido a que las inducen a tolerar altas concentraciones de metales pesados y promueven su crecimiento, mediante la fijación de nitrógeno, solubilización de fosfato, producción de sideróforos y de la ACC desaminasa, entre otros.

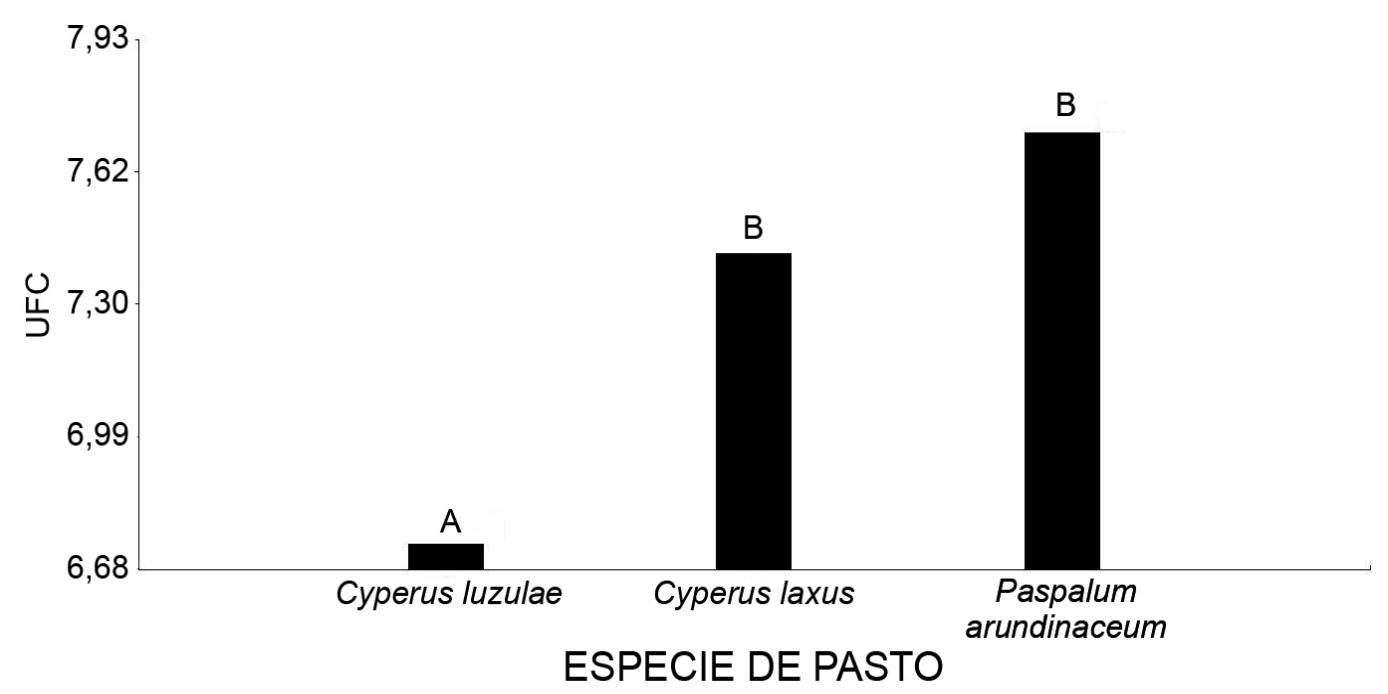

Figura 2. Diferencia de densidad poblacional entre los géneros Cyperus y Paspalum.

Evaluación in vitro de la resistencia a mercurio de bacterias endófitas: La tabla 2 muestra un total de siete bacterias endófitas asociadas a los géneros Cyperus y Paspalum, que crecieron a concentraciones de 350 y 400 ppm de mercurio. Cuatro morfotipos estaban asociados a la especie Paspalum arundinaceum: dos morfotipos, a Cyperus luzulae y un morfotipo, a Cyperus laxus. Como lo advierten Sorkhoh et al. (2010), el crecimiento a altas concentraciones de mercurio indica la resistencia de las bacterias endófitas a dicho metal.
Para Luo et al. (2011), la resistencia a altas concentraciones de metales que presentan las endófitas aisladas de plantas que crecen en ambientes contaminados, se debe a que se adaptan a vivir bajo condiciones de constante estrés por el metal. Algunos autores han descrito los beneficios de las endófitas resistentes a metales sobre el crecimiento y el desarrollo de plantas, entre ellos, se encuentran: la disminución de altas concentraciones de etileno en la planta que, en condiciones de estrés, provoca inhibición de su crecimiento; la producción de IAA, que estimula la división

Tabla 2. Resistencia a mercurio de bacterias endófitas asociadas a los géneros Cyperus y Paspalum.

\begin{tabular}{|c|c|l|}
\hline Aislado & $\begin{array}{c}\text { Concentración máxima de } \\
\mathbf{H g C l}_{2} \text { que resistió } \mathbf{( p p m )}\end{array}$ & $\begin{array}{c}\text { Especie de planta de la que } \\
\text { fue aislada }\end{array}$ \\
\hline 1CR3 & 400 & Paspalum arundinaceum \\
\hline 2AR1 & 400 & Cyperus luzulae \\
\hline 2BR4 & 400 & Cyperus luzulae \\
\hline 1BR1 & 400 & Paspalum arundinaceum \\
\hline 1DH1 & 400 & Paspalum arundinaceum \\
\hline 1ER4 & 350 & Paspalum arundinaceum \\
\hline 3DR3 & 400 & Cyperus laxus \\
\hline
\end{tabular}


celular; el mejoramiento del estado nutricional de la planta y la disminución de la fitotoxicidad, mediante la producción de sideróforos (Rajkumar et al. 2009; Ma et al. 2011).

Identificación molecular de bacterias endófitas resistentes a mercurio. El análisis filogenético del gen ARNr $16 \mathrm{~S}$ de bacterias endófitas resistentes a mercurio asociadas a los géneros Cyperus y Paspalum, se muestran en la figura 3.

Según éste análisis, cuatro de los aislados pertenecen a la clase betaproteobacteria: dos pertenecen a la clase Firmicutes y un aislado, a las Gammaproteobacteria.
Cabe destacar que el aislado 1CR3 presentó un 97\% de probabilidad de ser similar a Burkholderia cepacia, bacteria endófita aislada de $P$. arundinaceum. Esta especie bacteriana ha sido estudiada como endófita de Lupinus luteus resistente a níquel (Lodewyckx et al. 2001), pero hay escasos reportes sobre su capacidad de resistencia a mercurio. Es importante añadir que los aislados 2BR4 de $C$. luzulae y 1BR1 de $P$. arundinaceum presentaron una probabilidad del $100 \%$ de ser similares al género Burkholderia, el cual, también ha sido investigado por su capacidad de promoción del crecimiento vegetal y su resistencia a metales pesados, como el plomo y el cadmio (Jiang et al. 2008).

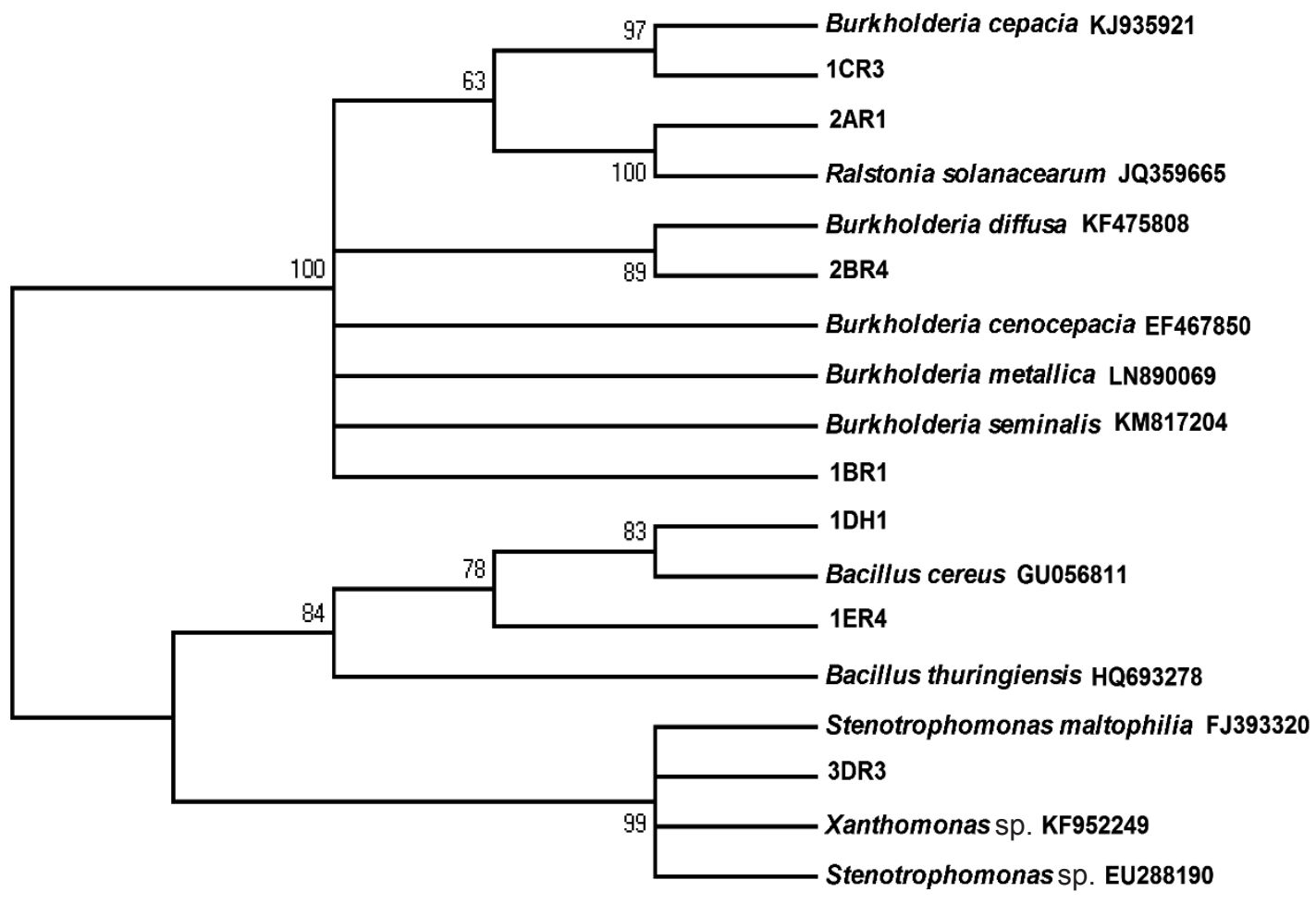

Figura 3. Árbol filogenético de máxima similitud de bacterias endófitas resistentes a mercurio.

El análisis filogenético mostró una probabilidad del $100 \%$ para el aislado 2AR1 de ser similar a Ralstonia solanacearum, endófita aislada de $C$. luzulae. La bacteria $R$. solanacearum, se considera un fitopatógeno de plantas, como la papa y la berenjena; sin embargo, Van Overbeek et al. (2004) la reporta como una endófita de plantas de tomate que es avirulenta y no ocasiona ninguna sintomatología. Es importante anotar que el género Ralstonia ha sido estudiado por su resistencia a mercurio; dichas bacterias fueron aisladas del suelo (Ranjard et al. 2000). Los aislados 1DH1 y 1ER4 de la especie $P$. arundinaceum presentaron gran probabilidad de similitud con el género Bacillus, reportado como endófito, resistente a metales, como cadmio, en Solanum nigrum (Luo et al. 2011) y níquel, en Oriza sativa (Pérez et al. 2015). Este género también ha sido investigado por presentar resistencia a mercurio; no obstante, la mayoría de las cepas estudiadas provienen de sedimentos marinos (Nithya et al. 2011).

Por su parte, el aislado3DR3 de C. laxus tuvo gran probabilidad de similitud con la familia Xanthomonadaceae. Ma et al. (2015) reporta bacterias del género Stenotrophomonas, como endófitas resistentes al cadmio. Por su parte, De et 
al. (2003) encontró que bacterias del género Xanthomonas tienen la capacidad de resistir altas concentraciones de mercurio; dichos aislados fueron obtenidos de ambientes marinos.

Con este estudio, se concluye que la falta de información derivada del escaso conocimiento acerca de las bacterias endófitas asociadas a tejidos de especies vegetales en ambientes contaminados con mercurio, conlleva a un desconocimiento de la diversidad de estas bacterias y su capacidad de resistir a diferentes concentraciones de mercurio. Estos estudios, no sólo son cruciales para el conocimiento básico de la dinámica ecológica, sino como información base para la aplicación de herramientas, que permitan aumentar o estabilizar la productividad y el rendimiento sostenible de sistemas agrícolas y servicios ambientales. En el departamento de Sucre no existe reporte alguno de estudios de presencia de bacterias en suelos y en plantas, contaminados con mercurio, por lo que esta investigación inicia un proceso de generación de conocimiento sobre esta temática y de posibles alternativas de solución frente a problemas de contaminación, por este contaminante en la región. Estudios posteriores evaluarán la capacidad de las bacterias endófitas resistentes a mercurio para promover el crecimiento de las plantas en ambientes contaminados con este metal, en el sur del departamento de Bolívar, Colombia.

Agradecimientos: Los autores agradecen al programa jóvenes investigadores e innovadores de Colciencias y a la Universidad de Córdoba, por toda la colaboración brindada. Conflicto de intereses: El manuscrito fue preparado y revisado con la participación de todos los autores, quienes declaramos que no existe conflicto de intereses, que ponga en riesgo la validez de los resultados presentados. Financiación: Este estudio fue financiado por la Universidad de Sucre.

\section{BIBLIOGRAFÍA}

1. ADRIANO, D.C. 2001. Trace elements in the terrestrial environment. Springer, New York. p.411-450.

\section{ARGUMEDO, M.; VIDAL, J.; MARRUGO, J. 2013. Mercurio} total en animales domésticos en Mina Santa Cruz, sur de Bolívar - Colombia. Rev. Col. Ciencia Animal. 5 (2):366-379.

3. BRYSON, C.; CARTER, R. 2008. The significance of Cyperaceae as weeds. Sedges, uses, diversity, and systematic of the Cyperaceae. Missouri: Monogr Syst. Bot. Mo. Bot. Gard. 108. p.15-101.

4. CASIERRA-POSADA, F.; AGUILAR-AVENDAÑO, O. 2007. Estrés por aluminio en plantas: reacciones en el suelo, síntomas en vegetales y posibilidades de corrección. Rev. Col. Ciencias Hort. 1(2):246-257.

5. CORDY, P.; VEIGA, M.; SALIH, I.; AL-SAADI, S.; CONSOLE, S.; GARCIA, O.; MESA, L.; VELÁSQUEZ-LÓPEZ, P.; ROESER, M. 2011. Mercury contamination from artisanal gold mining in Antioquia, Colombia: The world's highest per capita mercury pollution. Sci. Total Environm. 410-411:154-160.

6. CUI, W.; FANG, P.; ZHU, K.; MAO, Y.; GAO, C.; XIE, Y.; WANG, J.; SHEN, W. 2014. Hydrogen-rich water confers plant tolerance to mercury toxicity in alfalfa seedlings. Ecotoxicol. Environm. Safety. 105: 103-111.

7. DE, J.; RAMAIAH, N.; MESQUITA, A.; VERLEKAR, X. 2003. Tolerance to various toxicants by marine bacteria highly resistant to mercury. Marine Biotechn. 5(2):185-193.

8. ESCALANTE-ESPINOSA, E.; GALLEGOS-MARTÍNEZ, M.; FAVELA-TORRES, E.; GUTIERREZ-ROJAS, M. 2005. Improvement of the hydrocarbon phytoremediation rate by Cyperus laxus Lam. inoculated with a microbial consortium in a model system. Chemosphere. 59:405-413.

9. EVERS, G.; BURSON, B. 2004. Dallisgrass and other Paspalum species. In: Moser, L.E.; Burson, B.L.; Sollenberger, L.E. (eds). Warm-Season (C4) Grasses, Agronomy Monographs 45. eds. Madison, Wisconsin. p.681-713.

10. HOLMES, P.; JAMES, K.; LEVY, L. 2009. Is low-level environmental mercury exposure of concern to human health? Sci. Total Environm. 408(2):171-182.

11. INSTITUTO GEOGRÁFICO AGUSTÍN CODAZZI -IGAC-. 2015. ¿Cómo realizar latoma de muestras para suelos? Disponible desde internet en: http://www.igac.gov. co/wps/portal/igac/raiz/iniciohome/tramites/!ut/p/ c4/04_SB8K8xLLM9MSSzPy8xBz9CP0os3hHT3d JydDRwN3t0BXA0_vUKMwf28PI4NQI_2 C bEdFAJ67NCc!/?WCM_PORTLET $=\mathrm{PC}_{-}^{-} 7$ AIGOBB1A08AGF0ISG6J8NS30 (con acceso 26/03/2015).

12. JIANG, C.; SHENG, X.; QUIAN, M.; WANG, Q. 2008. Isolation and characterization of a heavy metalresistant Burkholderia sp. from heavy metalcontaminated paddy field soil and its potential in promoting plant growth and heavy metal 
accumulation in metal-polluted soil. Chemosphere. 72(2):157-164.

13. KABATA-PENDIAS, A. 2011. Trace elements in soils and plants. $4^{\text {th }}$ ed. CRC Press, Boca Ratón (Estados Unidos). p.304-312.

14. LODEWYCKX, C.; TAGHAVI, S.; MERGEAY, M.; VANGRONSVELD, J.; CLIJSTERS, H.; VAN DER LELIE, D. 2001. The effect of recombinant heavy metal resistant endophytic bacteria in heavy metal uptake by their host plant. Int. J. Phytoremed. 3:173187.

15. LÓPEZ-MARTÍNEZ, S.; GALLEGOS-MARTÍNEZ, M.; PÉREZ-FLORES, L.; GUTIÉRREZ-ROJAS, M. 2008. Contaminated soil phytoremediation by Cyperus laxus Lam. cytochrome p450 erod-activity induced by hydrocarbons in roots. Int. J. Phytoremed. 10:289-301.

16. LUO, S.; CHEN, L.; CHEN, J.; XIAO, X.; XU, T.; WAN, Y.; RAO, C.; LIU, C.; LIU, Y.; LAI, C.; ZENG, G. 2011. Analysis and characterization of cultivable heavy metal-resistant bacterial endophytes isolated from Cd-hyperaccumulator Solanum nigrum L. and their potential use for phytoremediation. Chemosphere. 85:1130-1138.

17. MA, Y.; PRASAD, M.; RAJKUMAR, M.; FREITAS, H. 2011. Plant growth promoting rhizobacteria and endophytes accelerate phytoremediation of metalliferous soils. Biotechnol. Adv. 29:248-258.

18. MA, Y.; OLIVEIRA, R.; NAI, F.; RAJKUMAR, M.; LUO, Y.; ROCHA, I.; FREITAS, H. 2015. The hyperaccumulator Sedum plumbizincicola harbors metal-resistant endophytic bacteria that improve its phytoextraction capacity in multi-metal contaminated soil. J. Environm. Managem. 156:62-69.

19. MARRUGO-NEGRETE, J.; DURANGO-HERNÁNDEZ, J.; PINEDO-HERNÁNDEZ, J.; OLIVEROVERBEL, J.; DÍEZ, S. 2015. Phytoremediation of mercury-contaminated soils by Jatropha curcas. Chemosphere. 127:58-63.

20. MORENO, F.; ANDERSON, C.; STEWART, R.; ROBINSON, B. 2008. Phytofiltration of mercury-contaminated water: Volatilisation and plant-accumulation aspects. Environm. Exp. Bot. 62:78-85.

21. NITHYA, C.; GNANALAKSHMI, B.; PANDIAN, S. 2011. Assessment and characterization of heavy metal resistance in Palk Bay sediment bacteria. Marine Environm. Res. 71(4):283-294.

22. OLARTE, L.; MUÑOZ, B.; BENAVIDES, G.; GARAVITO, F.; LUNA, C.; MEJÍA, L.; ROZO, E. 1979. Métodos analíticos del laboratorio de suelos. Instituto Geográfico Agustín Codazzi. 4a. ed. Bogotá, Colombia.

23. OLIVEIRA, M.; SANTOS, T.; VALE, H.; DELVAUX, J.; CORDERO, P.; FERREIRA, A.; MIGUEL, P.; TOTOLA, M.; COSTA, M.; MORAES, C.; BORGES, A. 2013. Endophytic microbial diversity in coffee cherries of Coffea arabica from southeastern Brazil. Can. J. Microbiol. 59:221-30.

24. PÉREZ, A.; ROJAS, J.; FUENTES, J. 2010. Diversidad de bacterias endófitas asociadas a raíces del pasto colosuana (Bothriochloa pertusa) en tres localidades del departamento de Sucre, Colombia. Acta Biol. Col. 15 (2):219-228.

25. PÉREZ, A.; ARROYO, E.; CHAMORRO, A. 2015. Resistencia a níquel en bacterias endófitas aisladas a partir de Oriza sativa en Colombia. Rev. Soc. Venez. Microbiol. 35:20-25.

26. POSCHENRIEDER, C.; BARCELÓ, J. 2003. Estrés por metales pesados. In: Reigosa, M.J., Pedrol, N., Sánchez, A. (eds.). Ecofisiología Vegetal. Madrid. p.413-442.

27. RAJKUMAR, M.; NORIHARU, A.; FREITAS, H. 2009. Endophytic bacteria and their potential to enhance heavy metal phytoextraction. Chemosphere 77:153160.

28. RANJARD, L.; BROTHIER, E.; NAZARET, S. 2000. Sequencing bands of ribosomal intergenic spacer analysis fingerprints for characterization and microscale distribution of soil bacterium populations responding to mercury spiking. Appl. Environm. Microbiol. 66(12):5334-5339.

29. SÁNCHEZ, E.; CURETTI, M. 2006. Los suelos salinos y sódicos. Fruticult. Diversific. 12(49):10-13.

30. SORKHOH, N.; ALI, N.; DASHTI, N.; AL-MAILEM, D.; AL-AWADHI, H.; ELIYAS, M.; RADWAN, S. 2010. Soil bacteria with the combined potential for oil utilization, nitrogen fixation and mercury resistance. Int. Biodeterior. Biodegr. 64:226-231. 
31. TERÁN-MITA, T.; FAZ, A.; SALVADOR, F.; AROCENA, J.; ACOSTA, J. 2013. High altitude artisanal small-scale gold mines are hot spots for mercury in soilsand plants. Environm. Poll. 173:103-109.

32. VAN OVERBEEK, L.; BERGERVOET, J.; JACOBS, F.; VAN ELSAS, J. 2004. The low-temperature-induced viable-but nonculturable state affects the virulence of Ralstonia solanacearum biovar 2. Phytopathology. 94:463-469.

33. VIDAL, J.; MARRUGO, J.; JARAMILLO, B.; PEREZ, L. 2010. Remediación de suelos contaminados con mercurio utilizando guarumo (Cecropia peltata). Ing. Desarrollo. 27:113-129.
34. WANG, Y.; GREGER, M. 2004. Clonal differences in mercury tolerance, accumulation, and distribution in willow. J. Environm. Quality. 33:1779-1785.

35. WEYENS, N.; VAN DER LELIE, D.; TAGHAVI, S.; VANGRONSVELD, J. 2009. Phytoremediation: plantendophyte partnerships take the challenge. Current Opinion Biotechn. 20:248-254.

36. YADAV, S. 2010. Heavy metals toxicity in plants: An overview on the role of glutathione and phytochelatins in heavy metal stress tolerance of plants. South Afr. J. Bot. 76:167-179.

Recibido: Julio 21 de 2015

Aceptado: Enero 27 de 2016

\section{Cómo citar:}

Pérez, A.; Martínez, D.; Barraza, Z.; Marrugo, J. 2016. Bacterias endófitas asociadas a los géneros Cyperus y Paspalum en suelos contaminados con mercurio. Rev. U.D.C.A Act. \& Div. Cient. 19(1): 67-76. 